\section{Organizational culture and internal control}

Sorin DOMNIŞORU,

University of Craiova,

E-mail: domnisorusorin@yahoo.com

Radu OGARCĂ, University of Craiova, E-mail: rfogarca@yahoo.com

Isabela DRAGOMIR, University of Craiova,

E-mail: isabela_dragomir@yahoo.com

\section{Albstract}

The paper proposes investigating the relationship between the organizational culture and internal control. The approach is a qualitative, constructive one. There is asserted and argued the thesis according to which between the two elements there is a one-to-one relationship, going on up to an extended overlapping between the organizational culture and the internal control environment. Though, our work emphasizes also the potential differences and distortions which may appear within the organizational activity between these important elements.

The identification of several factors which may enhance the synergy between the organizational culture and internal control, respectively the description of possible entities, processes and organizational relationships through which there could be made corrections and reciprocal adjustments between the two elements are the main results of the present research, with theoretical importance for the scientific and practical research for the organizational management and audit.

Keywords: Organizational culture, internal control, management, control environment

JEL Classification: M10, M14, M49

To cite this article:

Domnişoru, S., Ogarcă, R. and Dragomir, I. (2017),

Organizational culture and internal control, Audit Financiar, vol.

XV, no. 4(148)/2017, pp. 628-643, DOI:

10.20869/AUDITF/2017/148/628

To link to this article:

http://dx.doi.org/10.20869/AUDITF/2017/148/628

Received: 03.05.2017

Revised: 10.07.2017

Accepted: 11.07.2017 


\section{Introduction}

The internal control and organizational culture are two widely approached themes in the economic literature of the last decades. Nevertheless, the concepts have not been entirely clarified, their definition still having debatable areas.

The concept of internal control appeared as a practice in the USA at the beginning of the $20^{\text {th }}$ century, whereas in the economic literature it began to be extensively approached after the '50s (Hay, 1993).

In 1992 the Committee of Sponsoring Organizations of the Treadway Commission (COSO) issued the document "The Internal Control - General Framework", which, up to a certain extent, has brought a certain global alignment of practice and literature on this concept. Apostolou and Crumbley (2008) consider that, following this report the internal control (a much older concept strictly within the field of accounting) has extended its boundaries from the financial and accounting function to the entire entity.

The financial scandals at the beginning of the 2000s (Enron, Worldcom, Parmalat, etc.) led to the occurrence of the Sarbanes-Oxley law, which focuses on the efficiency of the enterprise's internal control system and on its rigorous/responsible assessment. This fact emphasizes the idea that the concept of "internal control" and the system of internal control should be clearly defined. Ambiguities should be eliminated also in respect of the implementation and assessment of the internal control system (Lakis and Giriunas, 2012).

In the last half of the century, especially influenced by the recent regulations mentioned above, the concept of "internal control", in some authors' view, "has gone out of haze" (Renard, 2016). In our view, it does not mean that there has been reached an unchangeable definition, but rather that a nucleus can be retrieved from all definitions, both form professional bodies, and researchers.

On the other hand, the organizational culture became a research theme for the researchers in the organizational field around the 1970s. According to Teehankee (1994), the first authors who used and/or tried to define the concept of organizational culture were: Margulies (1969); Beckhard (1969) - who uses the concept but does not define it; Schein (1968) - he used the phrase "organizational socialization", but the given definition could be considered close to that of organizational culture.
In the ' 80 s, on the background of Japanese firms' spectacular performance growth, paralleled by the decrease of American companies' performance, and the review of some managerial theories under the influence of these developments, respectively, a series of authors investigated the manner in which the organizational culture contributed to the organizations' performance (Ouchi, 1981; Peters and Waterman, 1982; Deal and Kennedy, 1982). The success of these papers turned the organizational culture into a widely approached topic in the professional literature related to organizations (Plakhotnik and Tonette, 2005).

Generally, the relationship between control and organizational culture has been in its turn widely studied (Andersen and Lueg, 2016). In these papers culture is seen as an element generating particular forms of organizational control. Thus, Ouchi (1980) speaks about the clan type control (accompanied by two other control mechanisms - market and bureaucratic control), based on common values and beliefs. Jaeger (1982) identifies two control styles within the multinational companies: formal, bureaucratic control - based on clear rules and regulations; and informal, cultural control - based on the existence of an implicit culture within the organization. Ray (1986) identifies three approaches of organizational control: bureaucratic (based on the control of compensations); humanistic (based on group social relationships) and the control through culture (based on the manipulation of the organization culture aimed at gaining attachment towards the organization and its objectives).

Rather surprisingly, the papers addressing the relationship between the internal control (as defined by the international professional bodies in the field) and the organizational culture are less visible.

Pfister (2009) encloses the most substantial approach of the relationship between organizational culture and internal control. The author identifies two challenges for his research: capturing the effect of organizational culture on the internal control efficiency and capturing the manner in which the internal control mechanisms influence the organizational culture. In order to answer these two challenges, the author proposes a controlorganizational culture framework. Unlike the researches within the accounting field, Pfister (20019) points out that in his approach culture is a variable which might be influenced by top-management, and not a contextual variable. 
Carataş et al. (2013) consider that, to maximise the organizational profit, the internal control should "match" the organizational culture, and that the organizational culture could be seen as the cornerstone for a sound internal control.

Lu and Wenchang (2015) analyse the relationship between organizational culture and internal control in terms of corporate governance mechanisms, approached from a humanistic perspective; the study emphasise the idea that the integration of the internal control and organizational culture may contribute to the sustainable development of the organization.

Gamboa Poveda et al. (2016) take inventory of the Spanish literature approaching the relationship between the organizational culture and internal control. The three authors' observation is that there are few articles having organizational culture or internal control as a main topic (in the title, keywords or abstract). The conclusion after reading the aforementioned literature is that, in the relationship with the internal control, culture may have a mediator effect (similarly as it has in the relationship with leadership and knowledge management, which are both variables used to extended the search).

Although Hernandez et al. (2016) limit their research at the level of small businesses, they come to a similar conclusion: internal control is a necessary, but not sufficient condition for good business management, performance measurement and profit increase. Moreover, the internal control system must be connected to the organizational culture.

Thus, we find out that the literature approaching the relationship between internal control and organizational culture is not very wide and, in addition, some of the papers mentioned above are limited to emphasizing the need of "matching" the two organizational elements, without going in-depth with the analysis.

In this context, the objective of our paper is to deepen the analysis of the interactions between the internal control and organizational culture, emphasizing the factors which might amplify the synergy between the two concepts and the sources of potential inaccuracies.

\section{Methodology of Scientific research}

The development of the article is based on a descriptive, qualitative research which resorts to an interpretative process of the subject matter under consideration. The paper considers the views from the professional literature on the meanings of the two concepts whose interconditionality is intended to be emphasized.

Combining the authors' theoretical vision and experience in management, control and governance, an attempt was made to bring into the theoretical area both the undesirable corporate events regarding the incapacity, disinterest or ignorance of the correlation between the internal control system and the organizational culture, and the good/leading examples of a balanced interlocking of organizational culture and internal control.

By study and comparison, there have been pointed out the similarities, discrepancies, and mostly subtle interpretations regarding the mentioned concepts with the purpose to show the importance of the relationship between them, without raising the claim of an exhaustive work.

\section{Review of the relevant professional literature}

The interest for the organizational culture and internal control was recovered along with the famous corporate failures (brought to the public's attention by thedot.com crisis, during 1999-2000, and later on, during the global financial crisis that started in 2007), as a desire to accomplish an ample examination of the causes which generated them.

The common basis of these events was the lack of responsibility at all the organizational levels, the remuneration systems encouraging unsustainable shortterm approaches, self-satisfaction induced by the long periods of prosperity, the rigidity and lack of proactivity, and last but not least, the human greed (Association of Chartered Certified Accountant, 2008).

Basically, the analysis of these events directed the attention, among other things, to the internal control and risk management, with an impact on the organizational culture, but all related to governance.

Therefore, in these cases the issue came up regarding the lack of ethical culture, supported by the management. Taking this fact into account, all recommendations for preventing similar situations also consider the organizational culture. Biegelman and Bartow (2012) state that only a culture of compliance not only with the law, but also with the principles of honesty and integrity represent the proactive solution for 
preventing some organizational mistakes. Similarly, IFAC speaks about the need to develop a culture to stimulate the organization's members to act in accordance with the risk management strategies and internal control policies, where the personal example of top-management has an important role (IFAC, 2012).

The organizational culture, figuratively speaking, represents the DNA of an entity, the "compass" orienting the attitude and conduct of the entity's employees. The employees are not "cells" left to chance; on the contrary, they are guided by the managers in their actions to achieve the entity's objectives. Given these conditions, a real challenge for leadership is setting up values and beliefs at the entity's level, in line with its advancement (Tabuena, 2016). Inevitably, the leaders permanently want to be sure that their guidance efforts do not deviate from the entity's path to success, so they need levers to assist them. In this respect, we consider the internal control, in the modern sense, as the system that consistently contributes to the entity's well-being, due to the fact that, among others, it facilitates the decisionmakers' access to good quality information.

Coming back to the unfortunate reality of the events mentioned, there is no doubt that the failure was generated by the leaders' lack of ability to create efficient mechanisms allowing the detection of (apparently insignificant) warning signals, useful for the prevention of disasters (KPMG, 2009).

The question arising is: "Which are the mechanisms that have the force to assert the quality of the entity's systems, processes and outcomes and to sound the alarm when monotony is established and the path is taken towards "good pleasure" and "today and after that dash it all!", but, more importantly, what are the implications for organizational culture in all these aspects?"

In our view, the organizational culture is responsible for creating and maintaining the perceptions among the employees and the manner in which they agree, accept and respect all the processes developed within the entity, including the leaders' authority and following their ideas, but also the procedures and measures they consider efficient to ensure the entity's performance. This vision also embodies the attention given to the internal control with role in ensuring that the path followed by the entity does not divert from the achievement of its objectives.

Therefore, there is no surprise that both the professional literature (Pfister, 2009; Carataş et al., 2013; Lu and Wenchang, 2015; Gamboa Poveda et al., 2016), and the various organizations/entities of international impact (KPMG, 2009; United States General Accounting Office, 1999) considered necessary that both culture and control be convergent and socially responsible.

For a better understanding of the synergy force of the two elements - organizational culture and internal control - in order to ensure an entity's success, we considered appropriate to expand the conceptual framework (conceptual versions) brought into discussion, but limited to some of the meanings of the two concepts described into the professional literature. The purpose of this endeavour is that of joining as much evidence as possible to ensure the sustainability of the research we initiated; we will point out strictly the concepts that we consider in accord with what we want to emphasize.

Thus, Schein (1990) defines the organizational culture as "a pattern of shared basic assumptions that the group learned as it solved its problems of external adaptation and internal integration that has worked well enough to be considered valid and, therefore, to be taught to new members as the correct way you perceive, think, and feel in relation to those problems".

On the other hand, "the organizational culture consists of interactions among critical masses of people with different preferences and past choices that have the capacity to wield critical influences upon each other, both in the short and long terms, within and beyond the confines of organizations and resource constraints" (Wu, 2008).

Mostly relevant for our research is also the idea advanced by Gerstner (2004), who considers: "the organizational culture is what people do without being told to".

By analysing and interpreting the content of these three assertions, we can state that they capture well the manner of running the actions within an entity and the interconnections created within it when the employees perform their tasks, as well as the guidance provided by the managers.

Schein (1990) describes the manner of building the organizational culture, its validation by the daily realities, but also its share between the organization's members. Although without an express mention, we consider that it is inhered the fact that the definition comprises both the leaders and the internal control which strengthens the opinions by the supplied information that the beliefs are right ("assumptions which functioned well enough to be considered valid"), meaning that they are in accordance 
with the entity's philosophy and could be passed on to the new members of the entity.

The meaning given by $\mathrm{Wu}(2008)$ describes the efforts of the leaders who pursue to build real families within the entity, which work together to achieve the same goal. In this case there can also be seen the presence of the control performed by leaders through their own approaches, decision and actions, by being always connected to the internal environment in order to know at any moment that the personnel does not divert from the organization's philosophy. If the management finds that the entity's activity is going the wrong way, it must take the right measures for the given situation in order to prevent it from taking a chronic form.

In a positive, and even non-realistic interpretation if confronted with the truth of the daily realities, of the definition given by Gerstner (2004) reveals the ideal of symbiosis between the organizational culture and internal control, in the sense that: the leaders' efforts to create a pro-active working environment tend to be reached, the induced state of control is one to encourage the creativity and it inhibit the immoral or incorrect actions as reported to the culture philosophy; the employees develop the ability to harmonize and line up their personal culture to the entity's organizational culture, knowing what to do and acting accordingly to support the entity's goals. If we revert to reason, we agree that in order for the employees' actions to bring added value to the entity, the support of an internal control mechanism that is discrete, and at the same time efficient and motivating is necessary.

These approaches are interesting, but are more inclined to emphasize the philosophic, spiritual side of the organizational culture without bringing enough "technical" aspects into the mix. Therefore, for a rigorous presentation, we find it necessary to quote The Business Dictionary, which considers the organizational culture as being the set of values and behaviours that contribute to the unique social and psychological environment of the entity that expresses in its self-image, activities and actions based on:

- the manner of organizing the activity, the attitude towards the employees, clients, as well as towards the entire community;

- the extent to which the controlled freedom is allowed in the process of decision-making, encouraging the development of new ideas and personal presentations;

- the manner of communication, information flow and interpersonal/structural relationship;

- the impression induced by the employment and career management policies and practices in order to achieve the common purposes.

\section{Figure no. 1. The organizational culture puzzle}

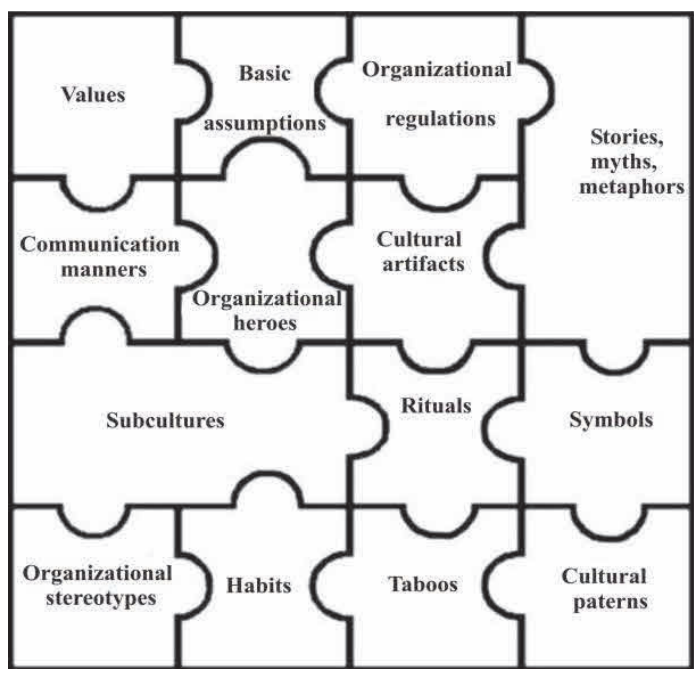

Source: Adaptation after Sulkovsky (2012) 
As it can be noticed, all the meanings we presented consider the organizational culture as bearing spiritual and customary valences. We consider that the organizational culture is not only a piece in a puzzle, but the entire puzzle, whose composition is clear and detailed, being created and refined over time. The power of this puzzle should not be neglected, because it impacts the manner in which the entity runs its activity (using the metaphor launched by Professor Sumantra Ghosal, 2005).

For clarity, in Figure no. 1 we supplied the main and defining elements of the organizational culture, which are ensuring its guidance and, at the same time, contribute to modelling the behaviours of the employees and the systems within the entity, but, to some extent, also influence those in contact with the entity. With regard to the components of the organizational culture, there are a lot of points of view in the professional literature and quite many doubts regarding their theoretical significance and practical scope. We chose what Sulkovsky (2012) considers, following the review of the most significant papers on this theme, to be a "canon" of the organizational structure components.

Of course there could be discussed the manner in which these elements contribute to the connectivity with the internal control, but we will limit our consideration to one of them, for example, habits. They may go from an alarming passivity up to enthusiastic proactivity. Obviously, each of these states of mind induces a certain culture to be faced by the internal control: in the first case it will have to fight against overwhelming inertia, whereas in the second case it will exult in innovation.

In our view, the organizational culture is not a shapeless and rigid mass, but a delicate, only relatively flexible "substance" which should grow consonantly with the necessary changes for ensuring the development of the reference entity. In our opinion, success depends on the leaders' ability to skilfully correlate/adapt/transform the elements of the organizational culture in accordance with the requirements of the evolution imposed by the external environment (without neglecting the internal one) and, in this context, their capacity to implement practical solutions (strategies, structures, processes) so that the entity could face any challenges. Otherwise, it is doomed to failure. The model proposed by Gordon (1991) regarding the development of the organizational culture under the influence of the industry-specific environment is in line with these coordinates (Figure no. 2).

\section{Figure no. 2. Organizational culture - determinants and incidence}

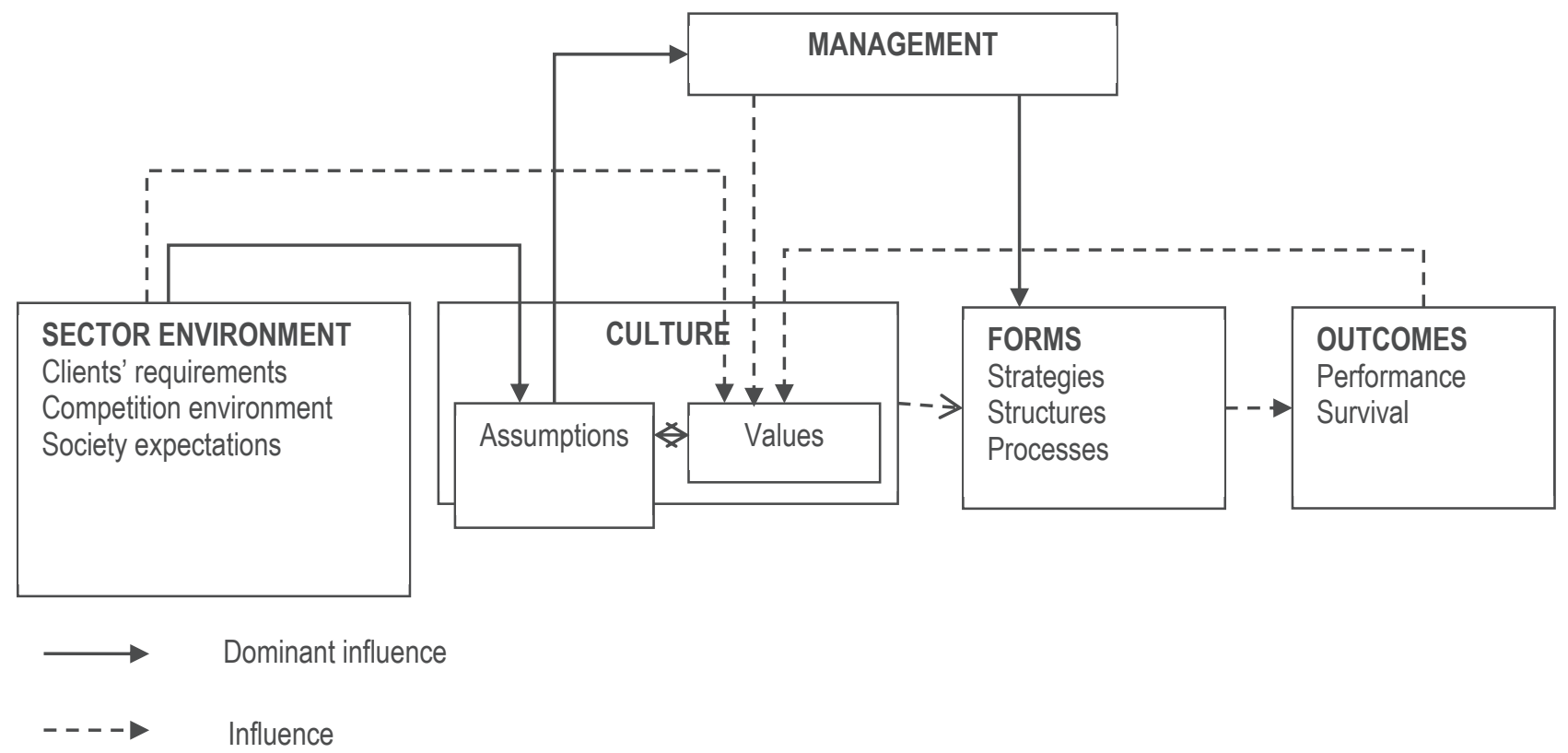

Source: Gordon (1991) 
Further on, we focus on internal control. Many definitions of internal control can be identified within the professional literature (relevant review of the literature on this topic could be found in Gafarov, 2009; Arwinge, 2014). The recent definitions are based mostly on the definition developed by COSO (1992), according to which internal control is "a process, effected by an entity's board of directors, management and other personnel, designed to provide reasonable assurance of the achievement of objectives in the following categories: effectiveness and efficiency of operations; reliability of financial reporting; compliance with applicable laws and regulations".

Considering that we pointed out enough elements to understand both the organizational culture and the internal control, we can move on to the development of the relationship description between these two: the manner in which internal control helps or does not help the organizational culture to "face the new challenges". Thus, due to the fact that the organizational culture is given by the principle of achieving things within the entity, the internal control shows if the manner of action has an appropriate direction in comparison with the entity's goals because it analyses the manner of achieving the actions and warns on the deviations which have occurred, or might occur, while offering the suggestions necessary for correcting them, going up to making all the actors socially responsible.

An interesting concept useful for our research was introduced by Johnson (1987). He speaks about the cultural web of the organization where he also includes the control systems (Figure no. 3).

The paradigm brings together the beliefs and values of the organization. It is remarkable that among the elements of the cultural web there are included the control systems and organizational structures which the professional literature does not generally place within the organizational culture frame and which are strongly connected to it.

\section{Figure no. 3. Cultural web of an organization}

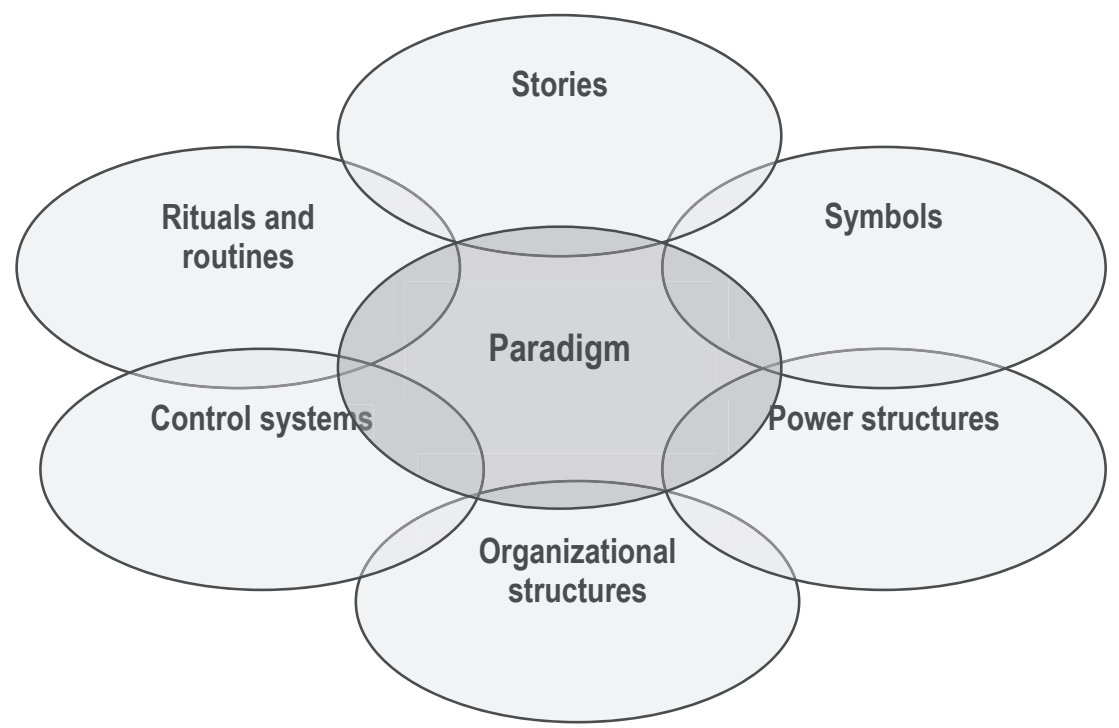

Source: Johnson, 1987

Sulkovski (2012) considers, and we agree with this view, that including the control systems and organizational structure into culture is equivalent to the impossibility of treating them as organizational sub-systems, similarly to the organizational culture. The analysis of any of the relationships between them would become thus irrelevant. Although the organizational structure and control systems have an important cultural determinant, they are not components or exclusive occurrences of the organizational culture. 
In this respect, Allaire and Firsirotu (1984) identifies three interconnected components within the organization:

- The social \& cultural system - comprising formal structures (including the control mechanisms), strategies, policies, processes;

- The cultural system - practically the organizational culture;

- The individual actors who relate to and interact differently with these systems in accordance with their own capacities, experiences, personalities.

The social \& cultural system and the cultural system are found, in the two authors' view, in a complex relationship, which is "mutually supportive", in "normal" conditions, but may become very tense, particularly when there are sudden pressures for organizational changes. Generally, the changes that occur more easily within the social \& cultural system cannot mirror themselves equally rapid within the cultural system, a fact leading to dissonance and loss of synchronism (Allaire and Firsirotu, 1984).

Finally, to better understand the relationships that may appear between the organizational culture and internal control, we consider that it is necessary to go back to the theoretical and practical approaches of organizational culture. Smirchich (1983) differentiated between the organizational culture as a variable and the organizational culture as a basic metaphor. In the first case, culture is seen as a variable among many others within the organization (structure, strategy, communication), which can be changed by management, as an organizational instrument to obtain performance. In the second case, culture is represented by a web of meanings and interpretations, socially disseminated and shared, with an axiological role, influencing every organizational component. Its developments are organic, generated by the aspirations, needs and desires of the organization's members at all levels, and they cannot be imposed by management. In the first approach, there is considered that the organization has a culture, whereas in the second one, the organization is a culture (Smirchich, 1983). In Figures no. 4 and no. 5 there are displayed the interactions between the organizational culture and other organizational systems (including the control systems) in terms of the two approaches.

\section{Figure no. 4. Culture as subsystem within the organization}

Figure no. 5. Culture as metaphor: fundamental dimension entering the other systems
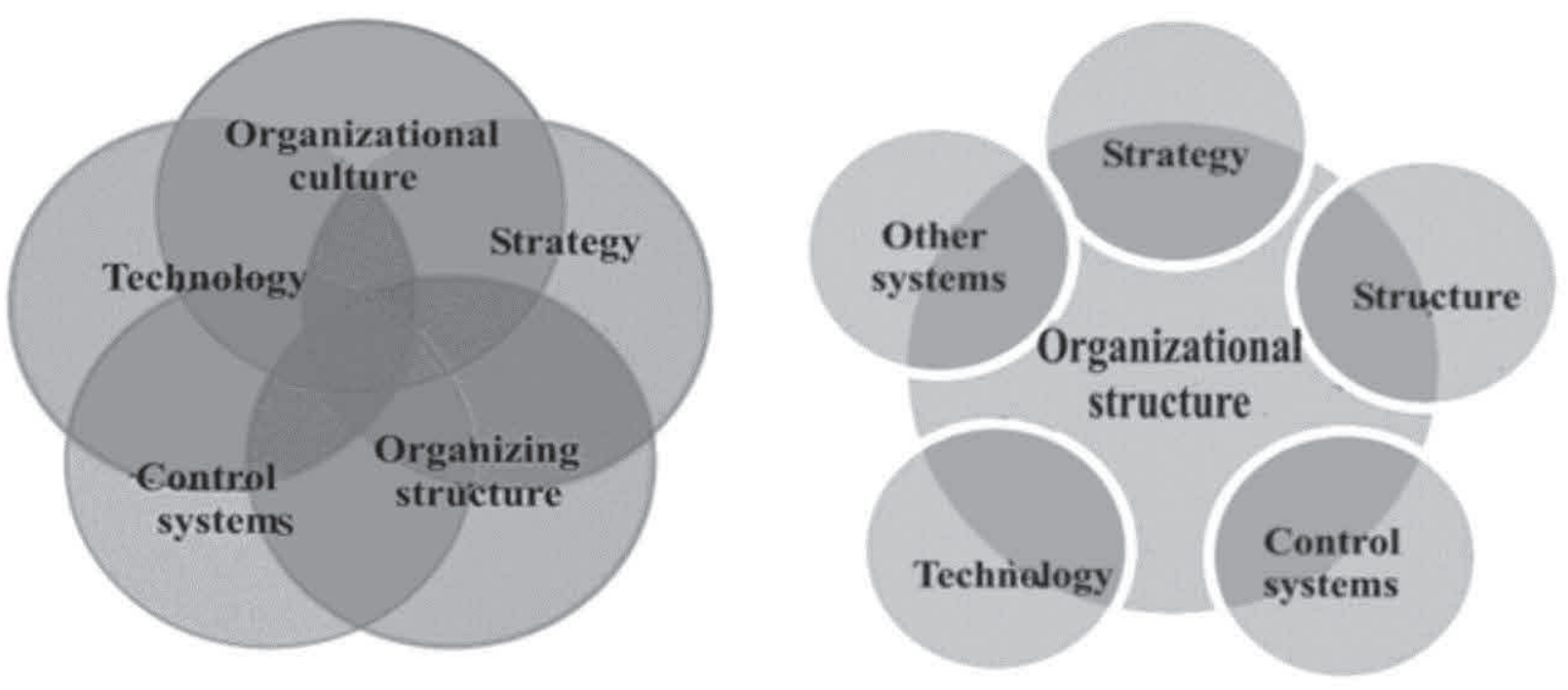

Source: Authors' design

No. 4(148)/2017 
Using these two figures we try to synthetically emphasise two of the interaction mechanisms. Thus, in the first case, culture is considered only as a common system, whereas, in the second case, they all "stem" from culture. Alevesson (2002) considers that the two approaches are not the only possibilities, but they are the extremes of a continuum, point of view to which we subscribe and on which we will build our arguments hereinafter. Therefore, we estimate that it is possible to consider integrally the interactions between culture and control only within some holistic approaches; individually they would lose essence. Based on this, we ascertain and assert the following ideas.

\section{Results of the research}

\subsection{Organizational culture - the „land” where internal control grows}

Guided by the above ideas, we consider the organizational culture as a source of control which creates a certain type of required spirits and attitudes, in order to teach, and even model behaviours, leading to the achievement of the entity's objectives. On the other hand, the effective internal control creates the spirits capable of "ensuring an environment dominated by comfort, stability and trust in terms of the organizing and functioning manner of the entity" (Domnişoru and Vînătoru, 2008).
All these make us estimate that while the organizational culture has rather historical valences, coming from the ancient past and it approaches the present rather strategically and forecasts only the fundamentals of the remote future, the internal control is (should be) sort of flexible and adjustable, remarkably tactile and rather directed towards recent history and predictable future, as it is presented in Figure no. 6. It should not be understood that one domain is neglected by the other, but they are focused slightly different in terms of chronology in order to get the same outcome: successful achievement of the entity's goals.

We consider the organizational culture as the most important driving force of any of the entities, being omnipresent in the configuration of the entity's structure, including in the design of the control system by setting the perceptions and configuring the working environment. Moreover, and more applied for our topic, as the Institute of Internal Auditors states, as well as Pfister (2009), that the culture of an organization is essential mostly for the effectiveness of internal control processes and systems. When the organizational culture is hostile, no system of internal control can be efficient (IIA, 2014), as it will have rigid, police-like issues inhibiting creativity and, implicitly, the possibility of innovation. Wright (2009) points out the fact that the organization members' attitudes and actions influence the internal controls, respectively the approaches are strongly influenced by the states of mind. This fact has cultural impacts as we consider the culture as the strongest shaper of the individual states of mind.

\section{Figure no. 6. Timeline of the organizational culture and internal control}

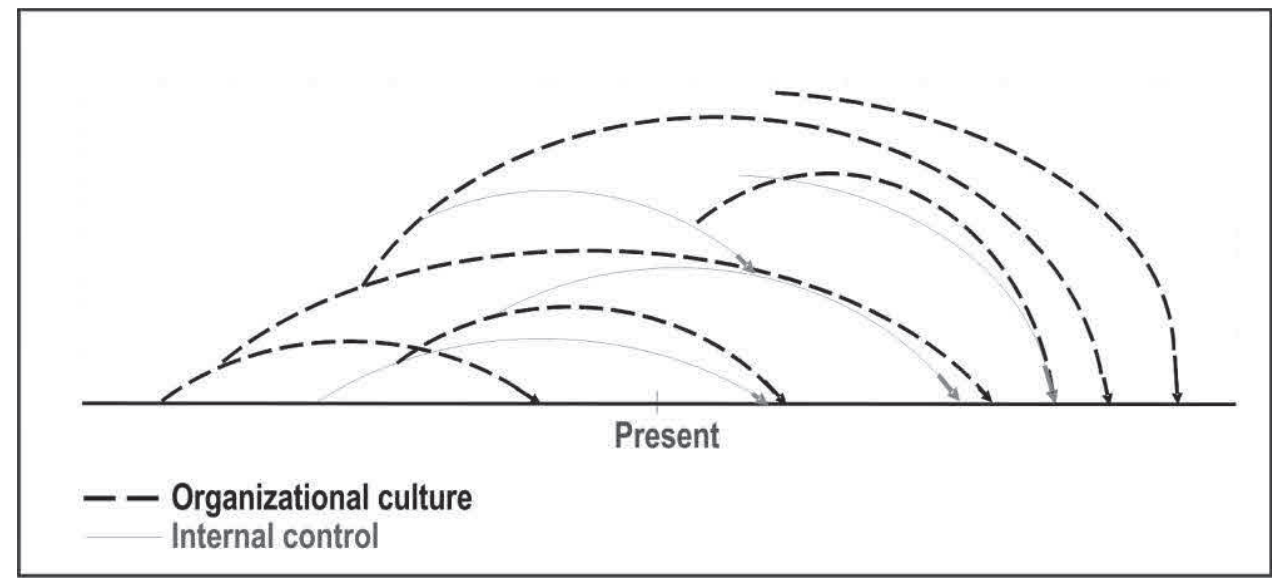

Source: Authors' design 
For a more suggestive picture, in Figure no. 7 we described the influence of the organizational culture on the internal control seen as "a state intended for communicating what happens, and especially how it happens within an entity" (Johnson, 2000), that is the one inducing the working consciousness (better proactive) and the (clear) manner of action in order to give assurance to the entity's leadership that it does not deviate from its objectives.

\section{Figure no. 7. Impact/influence of the organizational culture on the internal control}

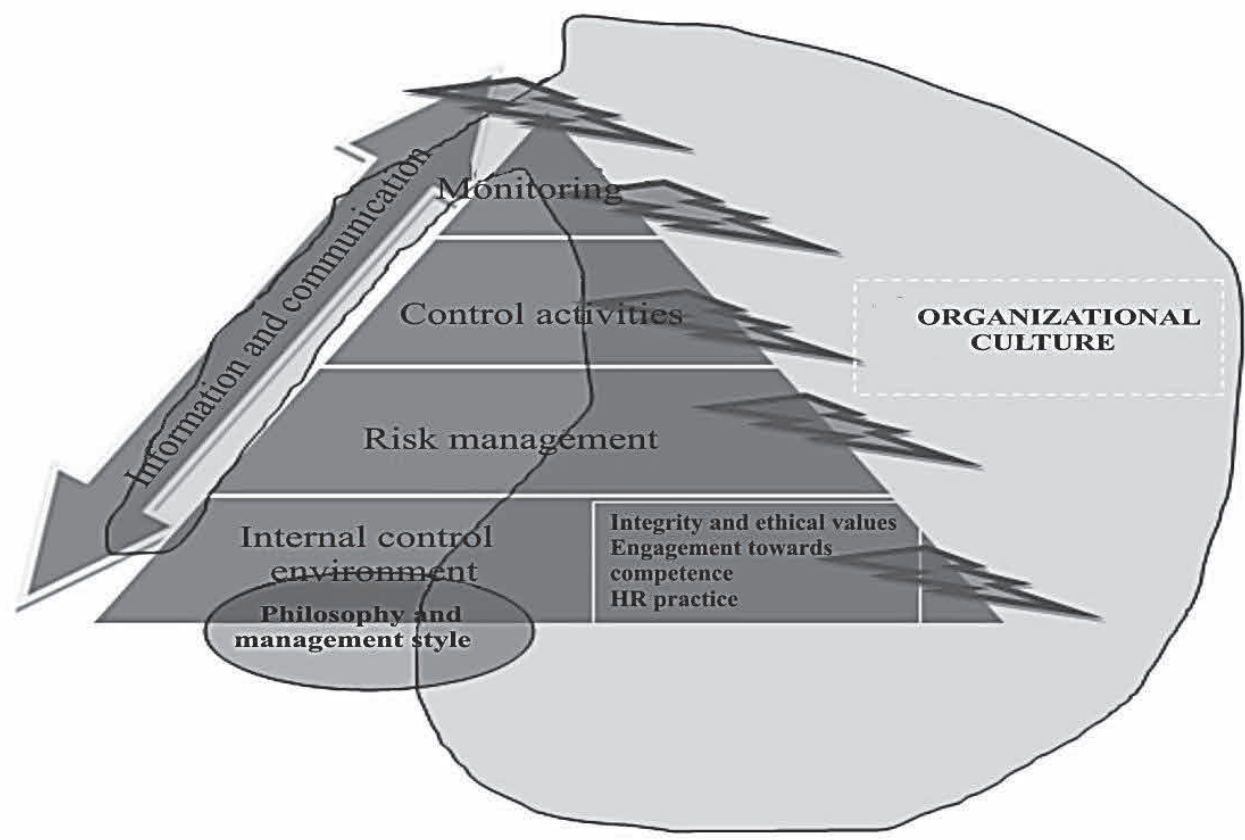

Source: Authors' design

If we provide further details, we can say that Figure no. 7 depicts at least two aspects:

- The organizational culture is, according to Roth (2010), the most important source of control (and maybe even rigor) within each organization, influencing each employee's behaviour, guiding the employee in accordance with the organizational expectations (McShane and Von Glinow, 2006). Thus, the organizations with ethical culture have less necessity for carefully supervising the employees, not to speak of manuals, organization charts and formal rules, procedures and strict controls (Nickels et al., 2011), which only stiffen, and sometimes are obsolete in comparison with the freedom of speaking. This idea could be briefly described as being the control exclusively through culture, a nice dream for the organizational practice.
- On the other hand, internal control could impact the organizational culture, meaning that its outcomes might transform certain elements of the organizational culture (organizational regulations, habits, manners of communication, etc.). In this respect, Andersen and Lueg (2016), in the wide professional literature review they make to analyse the relationship between the managerial control system and culture, quote two papers speaking about the fact that the introduction of a new bookkeeping system within the organization, which is more accurate, focused on control (Dent, 1991), and, respectively, the introduction of six-sigma (Busco and Scapens, 2011) have reshaped the culture of the studied organizations.

The organizational culture is, without a doubt, "the foundation" for all the components of the internal control 
system, particularly for the control environment. In this respect, we subscribe to the thesis according to which "the control environment substitutes for the organizational culture, state generated by the fact that elements like integrity, ethics, system of values, supervision, responsibility, performance assessment, interacts with the same intensity and force on both of them" (Japal, 2012). On the other hand, it is important to mention that the Institute of Internal Auditors defines the control environment, a component of internal control, as being "the attitude and actions of the management in terms of the importance of control within organization" (IIA, 2014).

At the same time, Arens et al. (2016) perceive the internal control environment as "an umbrella protecting the other components" of the internal control. In the view of the quoted authors, the personal example of managers, their attitude and behaviour with regard to the employees and third parties, the transparency they show contribute to building an honest internal control, because (as the American Institute of Certified Public Accountants states in the audit guide of "Assessing and Responding to Audit Risk In a Financial Statement Audit") the effectiveness of internal control cannot rise above the values of integrity and ethics of the people creating, managing and monitoring it. In other words, the right tone should be given at the top (for a detailed analysis of the concept "tone at the top" see Staicu et al., 2013). We must also point out that, in accordance with the COSO report from 2004 "Enterprise Risk Management - Integrated Framework", the tone at the top is considered a factor of influence for all eight components of risk management at organizational level, particularly for the internal environment.

We subscribe to the thesis according to which the integrity and ethical values are essential elements of the control environment, affecting the design, administration and monitoring of all internal control mechanisms and processes. At the same time, the integrity and ethical behaviour represent important determinants in the organizational culture of the entity (Figure no. 7).

In this context, the organizational culture does not only refer to substantiating and transmitting some values within the group but also to the manner in which people establish connections within the respective entity, to top managers descending among the common people and not isolating themselves "in the ivory tower" (paraphrasing Renard, 2016), to the art of developing a creative internal control, to the ability of implementing proactive systems and working states because the organizations that end up to be profitable are those which grant to people importance, as well as control on their work and trust (Peters and Waterman, 1982).

We consider that entities stand to gain as the organizational culture succeeds in directing the perception, conduct and attitude of the human resource so that it could perceive internal control as a manner of connecting to the entity's management, by supporting and rewarding the professionalism, promoting the best people on real bases known by the entire personnel of the entity, sound selection criteria, based on human quality, morality, professionalism, encouragement of creativity and granting freedom in accomplishing tasks, finding solutions instead of seeking guilty people, assessing the responsibility undertaken and increased caution to the inclination to punish a mistake made without intention as this could lead to systematic disappearance of initiative and creativity.

On this background, we appreciate that, for example, learning from mistakes might be rather seen as a source of enriching knowledge and gaining experience; in other words, a source of enrinching the organizational culture. Van Dyck et al. (2005) speak about cultural practice for a management of errors at organizational level: quick communication in respect of an error; analysis of error and dissemination at organizational level of the knowledge aquired following this analysis; control of losses. The control-learning dualism should be treated very carefully by the management; the managers should be extremely careful in respect of setting up the line between the error showing the lack of performance and the error as a learning oportunity (van Dick et al., 2015).

To the extent to which the organizational culture is that of the genuine empowerment culture, the control in the sense of classical examination/inspection converges inevitably towards zero or rather low levels. In this respect, we consider more than interesting the thesis supported by the Institute of Internal Auditors, according to which the organizational culture produces an important task in the internal control portfolio, in that a positive organizational culture which is oriented towards honesty and ethics has the capacity to create behaviours opened to implementing an appropriate control system contributing to increasing the general responsibility, even the social responsibility. 
Similarly, we come back to emphasise a phrase from The Business Dictionary, including in the organizational culture the "controlled freedom". This, in our opinion, is a common challenge both for the organizational culture and the internal control and a reflection of the organizational ambidextrousness. In support of this thesis there comes the philosopher Gabriel Liiceanu, who states in his work "On boundary" that: "human freedom is interpreted as a cluster of boundaries which are the condition of its exercise". In other words, freedom does not mean that anything could be done, or that the freedoms of others can be infringed, etc. Extrapolating, we state that ensuring the achievement of the proposed objectives cannot be done but directing human actions towards accurate goals which are good/reasonable in general and/or social views. Moreover, we can say that controlled freedom cannot be achieved without the concerted action of at least the two elements under consideration and harmonised by the internal control adapted to the organizational culture. There can be created the premises for a necessary balance at the organizational level between the autonomy and control (see also Xiao, 2017).

For a better consolidation of the stated theses, we attempt to present some eloquent aspects. Thus, if we speak about European countries and their national culture (mainly their legislative and institutional nature), we can mention that during 1991-1995, since the start of migration from Eastern Europe towards the West, it was observed that Western people did not have the necessary laws to solve some problems, which should penalize the obviously illegal actions in Eastern Europe. Due to the evolution of culture, the (organizational/national internal) control of occidental type "had wound down" in this area, other forces compensating for it. In this respect, the conclusion is that internal control, according to the level of culture, could be rather sanctioning (in the East) but mostly the promoter of the idea of correctness and, specifically, normality (in the West).

Similar, but in another field, is the situation within the business/patrimony entities. The control is developed in a certain manner in a culture where any idea is considered, without understanding that it is automatically brought in, but it is at least analysed, even tested for plausibility and performance, regardless of who it may have come from, which indicates that both organizational culture and internal control are proactive, encourage creativity and involvement as opposed to the ritual organizational culture (very canonical...) in strict compliant relationship with internal control and nothing else. We could say that the proactive culture implying a sensitive internal control is the best form of controlled freedom.

On the other hand, an organizational culture that drifts, loses direction and allows the development of a rigid and chaotic control system, characterized, for example, by the reign of a small group's pleasure, will only generate conflict, personal insecurity and work simulation states and attitudes, which consequently will keep the entity off its goals. In this respect, the following question arises as pertinent, "How could internal control avoid the philosophy of the organizational culture and influence it?" The answer to this question occurs as the internal control is in opposition with the culture of the entity where it was born, driving at subordonating/dominating it. This situation is possible in all the cases when the general environment inside the entity is characterized by stress and incapacity, fear and tiredness etc. It is the context when internal control is oriented towards aspects losing connection to reality and noble objectives.

Practically, such anomalies might occur when the organizational culture, for a period of time, forgets about the control call, the entity's defence and restoration system, which does not allow it to fall into desuetude and lets dishonest, obscure people build sub-cultures within itself, trying to take over as much power possible and to annihilate the mother culture. In other words, another culture can be generated, correlated to accomplishing the personal egoist objectives, appealing for this to techniques of insidious manipulation, diabolically combined with welfare praise.

Almost on the same line, Padilla et al. (2007) speak about the so called "toxic triangle" for any of the organizations, connecting a destructive leadership, susceptible employees and a conducive environment for distortions. The destructive leader (Ken Lay from ENRON is a leader in the business world) characterized by: charisma used for personal purpose; need/desire of power; narcissism; promoting a hatred, intimidation, conflict ideology (the example here is the ex-CFO of Enron, Andrew Fastow, who had always on his desk a cube with the following inscription: "When ENRON says it's going to 'rip your face off'... it means it will rip your face off!"). The susceptible employees are described to have: basic unmet needs (including social needs); 
negative auto-assessment: low psychic maturity; personal ambitions (exploited by the destructive leader); values and beliefs identical to those of the leader; unaccepted values at social level (greed, egoism). The conducive environment for such distorted behaviours refers to: instability; perception of imminent threats; the culture in which there is grown the avoidance of incertitude, collectivism, far distance from power; lack of a balance system (checks and balances) between the centres of power. Within such organizations, the internal control systems are used to discourage opinions and approaches opposed to those expressed by the leader, to undermine the members' trust in their abilities, to create an insecure environment.

A final aspect of the relationship between the organizational culture and internal control might be related to the following question: "What happens in this relationship when the leader changes?" Generally, the relationship between the organizational culture and internal control is a friendly one in which the organizational culture is the pacemaker and the internal control tunes up. Though, when the management changes or is essentially modified, this relationship is likely to become turbulent, in the sense that, althgough the organizational culture have the same almost temperate attitude, the internal control could become aggressive, it could push things and actions, systems and processes, even the organizational culture, succeeding or not, but affecting the organizational culture, sometimes even producing serious injuries, difficult or even impossible to be cured.

\section{Conclusions}

Overall, we concluded that between the two analysed institutions there is a one-to-one relationship. Of course, culture is the basis where there are created, developed and sometimes vanish the other elements of an entity, including the internal control at a given time, but sometimes leaving "tracks". We consider desirable that in the course of its existence and functioning, the innovative internal control should create as many elements as possible which are worth being included in the ethical organizational culture.

No doubt, organizational culture produces and reshapes behaviours, generates attitudes and determines states of mind, but, at the same time, it influences the manner in which there are configured the systems and the value attributed to them, including to the internal control. In this respect, there comes the idea according to which, by its content, the organizational culture is a source of control, a soft control - efficient and motivating (to the extent to which we discuss about a culture developing empowerment and compliance and it is not affected by certain pathologies), discrete or assertive, capable to correlate the approaches of the entity's employees with the ones desired by the organization in which the employees work.

On the other hand, it is unquestionable that internal control ends up influencing the organizational culture. This is mainly the result of the fact that internal control detects among others the prospect flaws of the organizational culture's value system. From another perspective, internal control could negatively affect the organizational culture, that is by taking advantage of some of its weaknesses and becoming possessive, for example, affecting up to annihilation any form of genuine positive leadership. It could also change the direction of the organizational culture, even by altering its substance.

Nevertheless, we consider that vigilance and balance of both institutions, transparency and attention to the feedback from the individual culture of the entity's employees and all stakeholders are elements worth being taken into consideration to prevent or correct any deviation from the constructive-positive non-connection of internal control and organizational culture.

The main limit of our research is the lack of completeness, respectively the focus on a low number of organizational cases and aspects. Nevertheless, we believe that the paper may be considered a sound basis for future research, such as emphasizing the synergies between the organizational culture and internal control or quantitative analysis of congruences and differences between the organizational culture and internal control environment.

Also, we believe that a future direction of interesting research might be the analysis of the relationships between the two elements, paying a higher attention to other factors which contribute to the configuration and changes of the organizational culture, in addition to the leadership we focused on within this article, such as: the dynamics of the business environment; pressures exercised by the business environment; the features of the local business environment; characteristics of the company's employees (Kuznetsov, 2014), national culture (Sim, 2009), etc. 


\section{REFERENCES}

1. Allaire, Y. şi Firsirotu, M.E. (1984), Theories of organizational culture, Organization studies, vol. 5, no. 3, pp. 193-226, DOI 10.1177/017084068400500301.

2. Alvesson, M. (2012). Understanding organizational culture, 2nd Edition, London: Sage Publications.

3. Andersen, C.V. şi Lueg, R. (2016), Does culture matter?-A systematic literature review on how culture interacts with management control systems, available at SSRN:

https://ssrn.com/abstract=2890880.

4. Apostolou, N. şi Crumbley, D.L. (2008), The tally stick: The first internal control?, Forensic Examiner, vol. 17, no. 1, pp. 60-62.

5. Arens, A.A., Hogan, C.E., Beasley, M.S. şi Randal, J.E. (2016), Auditing and Assurance Services: An integrated Approch (16th Edition), United States: Publisher Pearson Education.

6. Arwinge, O. (2014), Internal control in the financial sector: A longitudinal case study of an insurance company (Doctoral dissertation, Uppsala universitet).

7. Association of Chartered Certified Accountant (2008), Corporate Governance and the Credit Crunch, available at

http://www.accaglobal.com/content/dam/acca/glob al/PDF-technical/corporate-governance/cg_cc.pdf, accessed 20.02.2017.

8. Beckhard, R. (1969), Organization development: Strategies and models, Reading Mas: Addison Wesley.

9. Biegelman, M. T. şi Bartow, J. T. (2012), Executive roadmap to fraud prevention and internal control: Creating a culture of compliance, New Jersey: John Wiley \& Sons.

10. Busco, C. şi Scapens, R. W. (2011), Management accounting systems and organisational culture: Interpreting their linkages and processes of change, Qualitative Research in Accounting \& Management, vol. 8, no. 4, pp. 320-357, DOI 10.1108/11766091111189873.

11. Carataş, M.A., Spătariu, E.C. şi Trandafir, R.A. (2013), Internal audit, internal control and organizational culture - active ingredients in conquering the crisis, Ovidius University Annals, Economic Sciences Series, vol. 13, no. 2, pp. 553-557.

12. Committee of Sponsoring Organizations of the Treadway Commission (COSO) (1992), Internal control - Integrated Framework, New York: AICPA.

13. Committee of Sponsoring Organizations of the Treadway Commission (COSO), (2004), Enterprise Risk Management - Integrated Framework, New Jersey: AICPA.

14. Deal, T.E. şi Kennedy, A.A. (1982), Corporate cultures: The rites and rituals of corporate life, Reading, MA: Addison-Wesley.

15. Dent, J.F. (1991), Accounting and organizational cultures: a field study of the emergence of a new organizational reality, Accounting, Organizations and Society, vol. 16, no. 8, pp. 705-732, DOI 10.1016/0361-3682(91)90021-6.

16. Domnişoru, S. şi Vînătoru, S.S. (2008), Audit şi control intern - preliminarii conceptuale şi procedurale, Craiova, Editura Sitech.

17. Gamboa Poveda, J.E., Campuzano Rodriguez, M.A. şi Cabezas Cabezas, R.F. (2016), The challenge of organizational culture in internal control, REVISTA PUBLICANDO, vol. 3, no. 7, pp. 449-458.

18. Gafarov, T. (2009), Financial reporting quality control for internal control implementation (Doctoral dissertation, Brno University Of Technology).

19. Gerstner, L.V. (2004), în cadrul summit-ului de afaceri World Business Forum New York, available at http://www.tmiworld.com/ro/blogs/worldbusiness-forum-new-york-mai-2004, accessed 20.02.2017.

20. Ghosal, S. (2005), Want success? Change the smell of your workplace!, Rediff Business, available at http://www.rediff.com/money/ 2005/mar/10bspec.htm, accessed 30.03.2017.

21. Gordon, G.G. (1991), Industry determinants of organizational culture, Academy of Management Review, vol. 16, no. 2, pp. 396-415, DOI 10.5465/amr.1991.4278959. 
22. Hay, D. (1993), Internal control: How it evolved in four English-speaking countries, The Accounting Historians Journal, vol. 20, no. 1, pp. 79-102, DOI 10.2308/0148-4184.20.1.79.

23. International Federation of Accountants (2012), Evaluating and Improving Internal Control in Organizations, available at http://www.ifac.org/system/files/publications/files/E valuating $\% 20$ and $\% 20$ Improving $\% 20$ Internal $\% 20 \mathrm{Co}$ ntrol\%20in\%200rganizations\%20\%20updated\%207.23.12.pdf, accessed 01.03.2017.

24. Jaeger, A.M. (1982), Contrasting control modes in the multinational corporation: Theory, practice, and implications, International Studies of Management \& Organization, vol. 12, no. 1, pp. 59-82, DOI 10.1080/00208825.1982.11656333.

25. Japal, S. (2012), Comments on COSO revised Internal Control - Integrated Framework (2010), available at https://soniajaspal.wordpress.com/2012/01/05/com ments-on-coso-revised-framework-internal-controlintegrated-framework/, accessed 01.02.2017.

26. Johnson, G. (1987), Strategic change and the management process, Blackwell.

27. Johnson, G. (2000), Strategy through a cultural lens: Learning from managers' experience. Management Learning, vol. 31, no. 4, pp. 403-426, DOI 10.1177/1350507600314001.

28. KPMG (2009), Internal Control: A Practical Guide, pp. 23, available at http://www.ecgi.org/codes/documents/kpmg_intern al_control_practical_guide.pdf, accessed 23.03.2017.

29. Kuznetsov, A. (2014), Synergy of corporate culture and financial control in the chaotic environment, Journal of Finance and Accounting, vol. 2, no. 6, pp. 21-30, DOI 10.11648/j.jfa.s.2014020601.14.

30. Lakis, V. şi Giriunas, L. (2012), The concept of internal control system: Theoretical aspect, Ekonomika, vol. 91, no. 2, pp. 142-152.

31. Liiceanu, G. (1994), Despre limită, Bucureşti: Editura Humanitas.

32. Lu, X.U. şi Wenchang, L.I. (2015), The study on relationship between internal control and enterprise culture-based on corporate governance mechanism, International Business and Management, vol. 10, no. 1, pp. 82-87.

33. Margulies, N. (1969), Organizational culture and psychological growth, The Journal of Applied Behavioral Science, vol. 5, no. 4, pp. 491-508, DOI 10.1177/002188636900500403.

34. McShane, S.L. şi Von Glinow, M. (2006), Organizational Behaviour. Emerging Realities for The Workplace Revolution, 4thed McGraw Hill Companies Inc.

35. Nickels, G., McHugh, J.M. şi McHugh, S.M. (2011), Understanding Business, 9thed. Irwin, McGraw-Hill New York.

36. Ouchi, W.G. (1980), Markets, bureaucracies, and clans, Administrative Science Quarterly, vol. 25, no. 1, pp. 129-141, DOI 10.2307/2392231.

37. Ouchi, W.G. (1981), Theory Z: How American business can meet the Japanese challenge, Reading, MA: Addison-Wesley Publishing Company.

38. Padilla, A., Hogan, R., şi Kaiser, R.B. (2007), The toxic triangle: Destructive leaders, susceptible followers, and conducive environments, The Leadership Quarterly, vol. 18, no. 3, pp. 176-194, DOI 10.1016/j.leaqua.2007.03.001.

39. Peters, T.J. şi Waterman, R.H. (1982), In search of excellence: Lessons from America's bestrun companies, New York: Harper \& Row.

40. Pfister, J. (2009), Managing Organizational Culture for Effective Internal Control: From Practice to Theory, Springer Physica-Verlag, Berlin Heidelberg.

41. Plakhotnik, M.S. şi Rocco, T.S. (2005), Organizational Culture: A Literature Review of the AHRD 1994-2005 Proceedings, Florida International University, USA.

42. Ray, C.A. (1986), Corporate culture: the last frontier of control?, Journal of management studies, vol. 3, no. 3, pp. 287-297, DOI 10.1111/j.1467-6486.1986.tb00955.x.

43. Renard, J. (2016), Théorie et pratique de l'audit interne, neuvième edition, Groupe Eyrolles, Paris.

44. Roth, J. (2010). Best Practices: Evaluating the Corporate Culture, Published by Altamonte Springs, Fla.: Institute of Internal Auditors. 
45. Schein, E.H. (1968), Organizational socialization, Industrial Management Review, vol. 9, no. 2, pp. 1-16.

46. Schein, E.H. (1990), Organizational culture, American Psychologist, vol. 45, no. 2, pp. 109-119.

47. Sim, M. (2009), National culture effects on groups evaluating internal control, Managerial auditing journal, vol. 25, no. 1, pp. 53-78, DOI 10.1108/02686901011007306.

48. Smircich, L. (1983), Concepts of culture and organizational analysis, Administrative Science Quarterly, vol. 28, no. 3, pp. 339-358, DOI $10.2307 / 2392246$.

49. Sulkovsky, L. (2012), Elements of organizational culture - theoretical and methodological problems, Management, vol. 16, no. 2, pp. 63-71, DOI 10.2478/v10286-012-0056-y.

50. Staicu, A. M., Tatomir, R. şi Lincă, A. C. (2013), Determinants and consequences of tone at the top, International Journal of Advances in Management and Economics, vol. 2, no. 2, pp. 76-88.

51. Tabuena, J. (2016), Companies and regulators are paying more attention to getting culture right, available at http://misti.com/audit-newstrends/auditing-corporate-culture-a-new-imperative, accessed 20.02.2017.

52. Teehankee, B. (1994), Organizational culture: A critical review of literature, DLSU Dialogue: An Interdisciplinary Journal for Cultural Studies, vol. 27, no. 1, pp. 67-92.

53. The Business Dictionary (2017), available at http://www.businessdictionary.com/definition/organi zational-culture.html, accessed 01.02.2017.
54. The Institute of Internal Auditors (IIA) (2014), Culture and internal control, available at https://www.iia.org.uk/resources/ethics,-valuesand-culture/organisational-culture/cultureandinternal-control/, accessed 02.02.2017.

55. United States General Accounting Office (1999), Standards for Internal Control in the Federal Government, available at http://www.gao.gov/special.pubs/ai00021p.pdf, accessed 12.09.2016.

56. Van Dyck, C., Frese, M., Baer, M. şi Sonnentag, S. (2005), Organizational error management culture and its impact on performance: a two-study replication, Journal of Applied Psychology, vol. 90, no. 6, pp. 1228-1240, DOI 10.1037/00219010.90.6.1228.

57. Vargas-Hernández, J.G., Casas Cardenaz, R. şi Calderón Campos, P. (2016), Internal control and organizational culture in small businesses: A conjunction to competitiveness, Reuna, vol. 21, no. 2, pp. 5-22.

58. Wright, R.M. (2009), Internal Audit, Internal Control and Organizational Culture, available at http://vuir.vu.edu.au/1989/1/R-M-Wright-Thesis2009.pdf, accessed 02.02.2017.

59. Wu, J.Y. (2008), A general behavior model and new definitions of organizational cultures, Journal of Socio-Economics, vol. 37, no. 6, pp. 2535-2545, DOI 10.1016/j.socec.2007.10.002.

60. Xiao, Q. (2017), Control or Autonomy? A Case Study of two Organizational Forms in the Zhangjiakou Internal Migrant Organization, Public Organization Review, pp. 1-15. 